\title{
Cytology Brushing of a Pancreas Cyst Wall for the Diagnosis of Cystic Neuroendocrine Tumor: When FNA Fails
}

\author{
Ihab I. El Hajj, MD, MPH, ${ }^{1}$ Robert E. Emerson, MD, ${ }^{2}$ Mohammad Al-Haddad, MD, MSc ${ }^{1}$
}

${ }^{1}$ Department of Internal Medicine, Division of Gastroenterology and Hepatology, Section of Interventional Endoscopy, Indiana University School of Medicine, Indianapolis, IN

${ }^{2}$ Department of Pathology and Laboratory Medicine, Indiana University School of Medicine, Indianapolis, IN

\section{Corresponding author:}

Ihab I. El Hajj, MD, MPH

Assistant Professor of Medicine

Indiana University School of Medicine

550 N University Blvd, Suite 1634E

Indianapolis, IN 46204

Phone: $317-274-3255$

Fax: 317-948-0164

Email: ielhajj@iu.edu

\section{Case}

A 67 year old male patient presented with mid upper abdominal pain for 2 months. No history of pancreatitis or weight loss. Exam was unremarkable. Labs: normal pancreatic and liver enzymes. CT abdomen: $2.5 \mathrm{~cm}$ cystic lesion in the body of the pancreas. Upper EUS: unilocular $26 \mathrm{~mm}$ cyst, thin wall $(1.5 \mathrm{~mm})$, no septations, and no mural nodules. FNA using $19 \mathrm{G}$ needle yielded $3 \mathrm{mLs}$ of thin, straw-colored fluid. Air dried smears were hypocellular on immediate cytology review. Echobrush (Cook Medical Inc., Bloomington, IN, USA) was advanced through the 19 G needle to brush the cyst wall (Fig. 1A). Weakly cohesive cell groups with round nuclei were noted on air dried smears, suggestive of cystic neuroendocrine tumor (NET) (Fig. 1B). Immunostains positive for synaptophysin and chromogranin. Cyst fluid CEA $47 \mathrm{ng} / \mathrm{ml}$, and genetic analysis revealed no k-ras point mutation or loss of heterozygosity. One month later, the patient underwent middle

This is the author's manuscript of the article published in final edited form as:

El Hajj, I. I., Emerson, R. E., \& Al-Haddad, M. (2017). Cytology Brushing of a Pancreas Cyst Wall for the Diagnosis of Cystic Neuroendocrine Tumor: When FNA Fails. Digestive and Liver Disease.

https://doi.org/10.1016/j.dld.2017.05.007 
segment pancreatectomy (Fig. 2A). Pathology showed R0 resection of a $2.5 \mathrm{~cm}$ unifocal welldifferentiated cystic NET, pT2pN0pMx (Fig. 2B).

EchoBrush has been shown to be safe and to provide cytologically superior specimens compared to FNA mainly because of the higher yield of epithelial cells and intracellular mucin [1]. This technique is recommended when FNA falls short of a suspected diagnosis.

\section{CONFLICT OF INTERREST}

Conflict of interest: None to report.

Financial disclosure: None to report.

Informed consent was obtained for this case report. 


\section{References}

[1]. Al-Haddad M, Gill KR, Raimondo M, Woodward TA, et al. Safety and efficacy of cytology brushings versus standard fine-needle aspiration in evaluating cystic pancreatic lesions: a controlled study. Endoscopy 2010;42:127-132. 
Legends (these are included here just for clarification, I understand that these won't be included in the final version).

Fig. 1A. Linear endoscopic ultrasound showing EUS-guided brushing of a cystic pancreatic lesion using the EchoBrush introduced through the $19 \mathrm{G}$ needle.

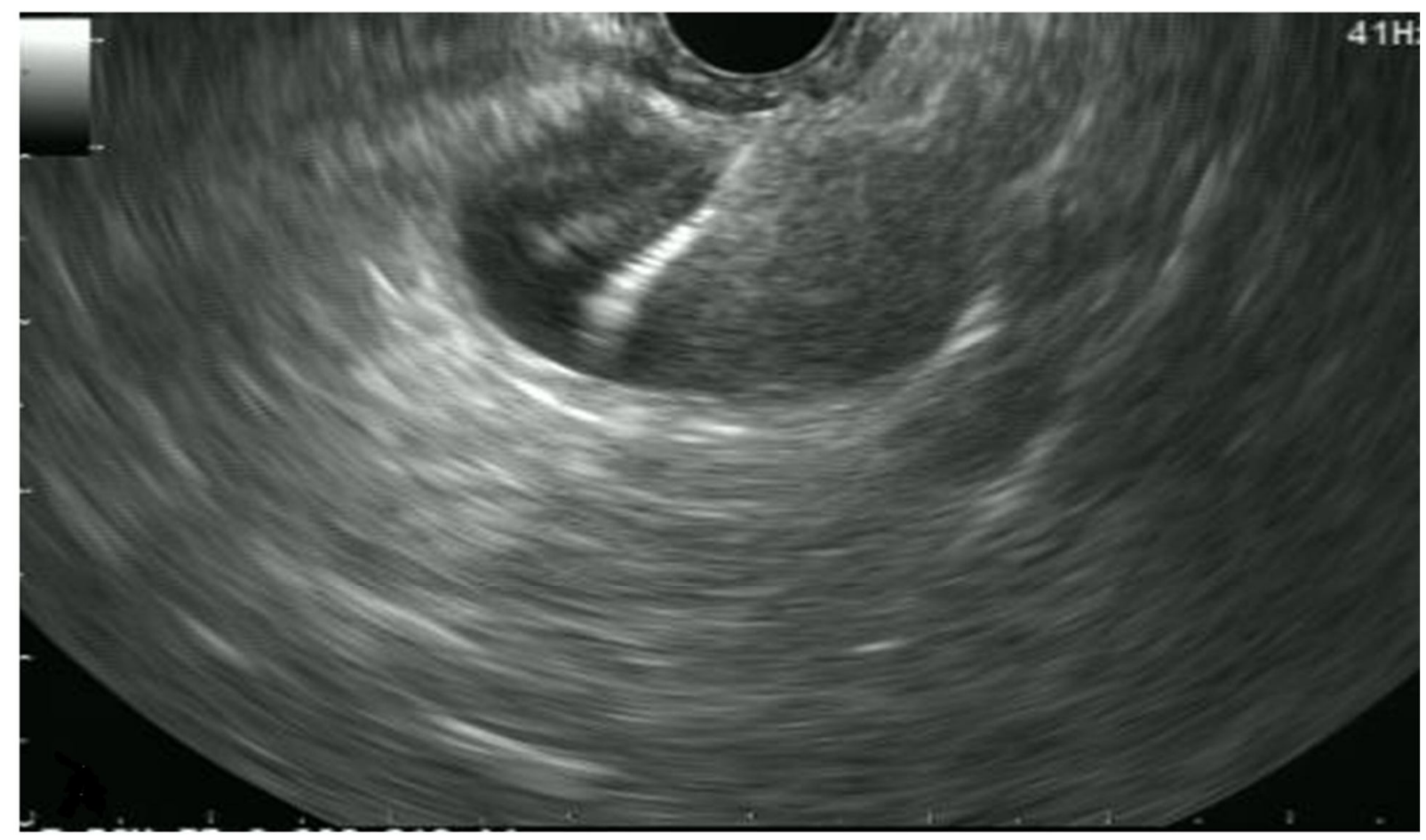

Fig. 1B. Post-brush (of the cyst wall) aspirate showing weakly cohesive cell groups with round nuclei and moderate amount of cytoplasm, strongly suggestive of cystic neuroendocrine tumor (Diff Quick, original magnification x 200). 


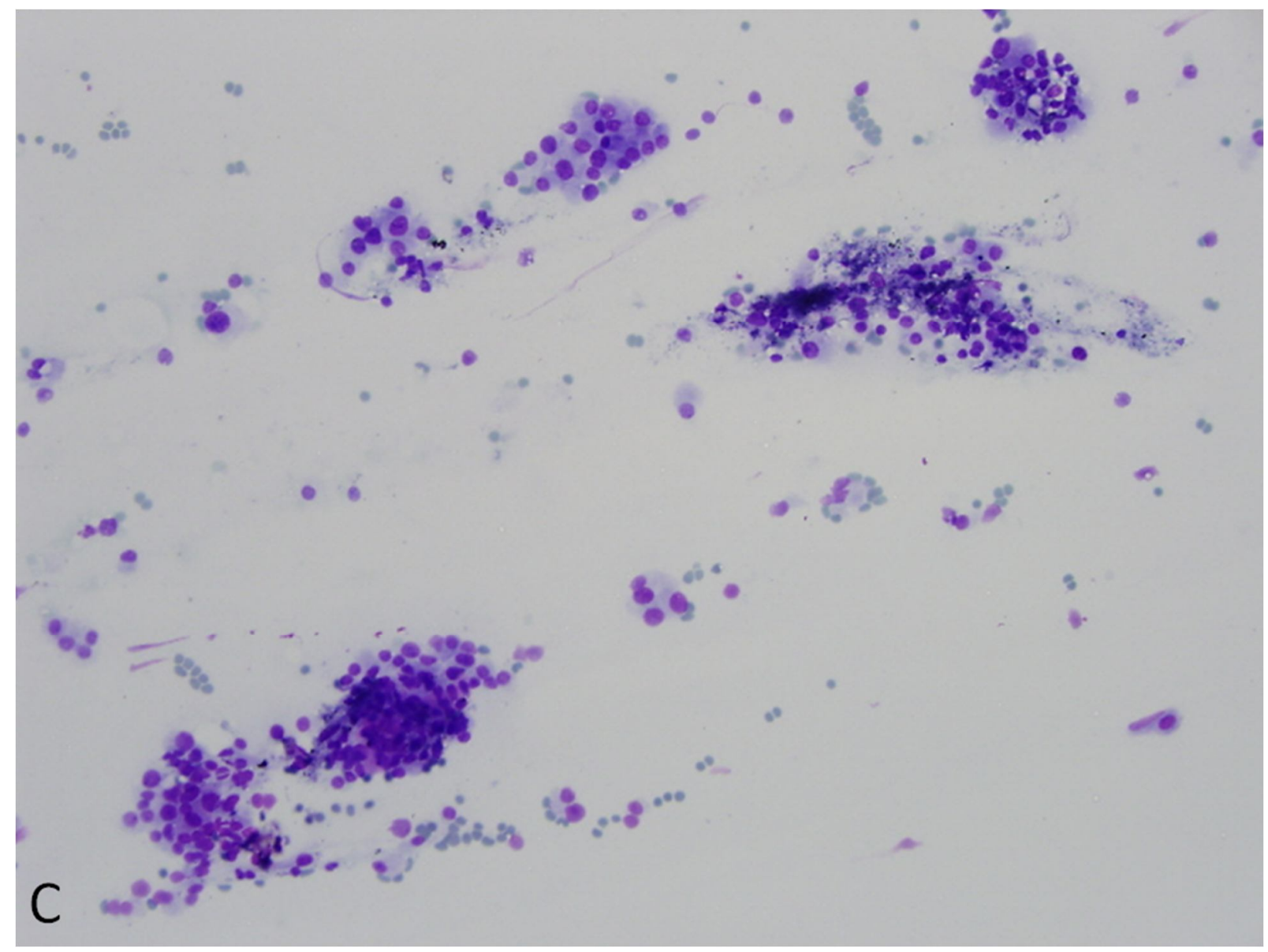

Fig. 2A. Surgical specimen showing a $2.5 \mathrm{~cm}$ unifocal cystic tumor. 


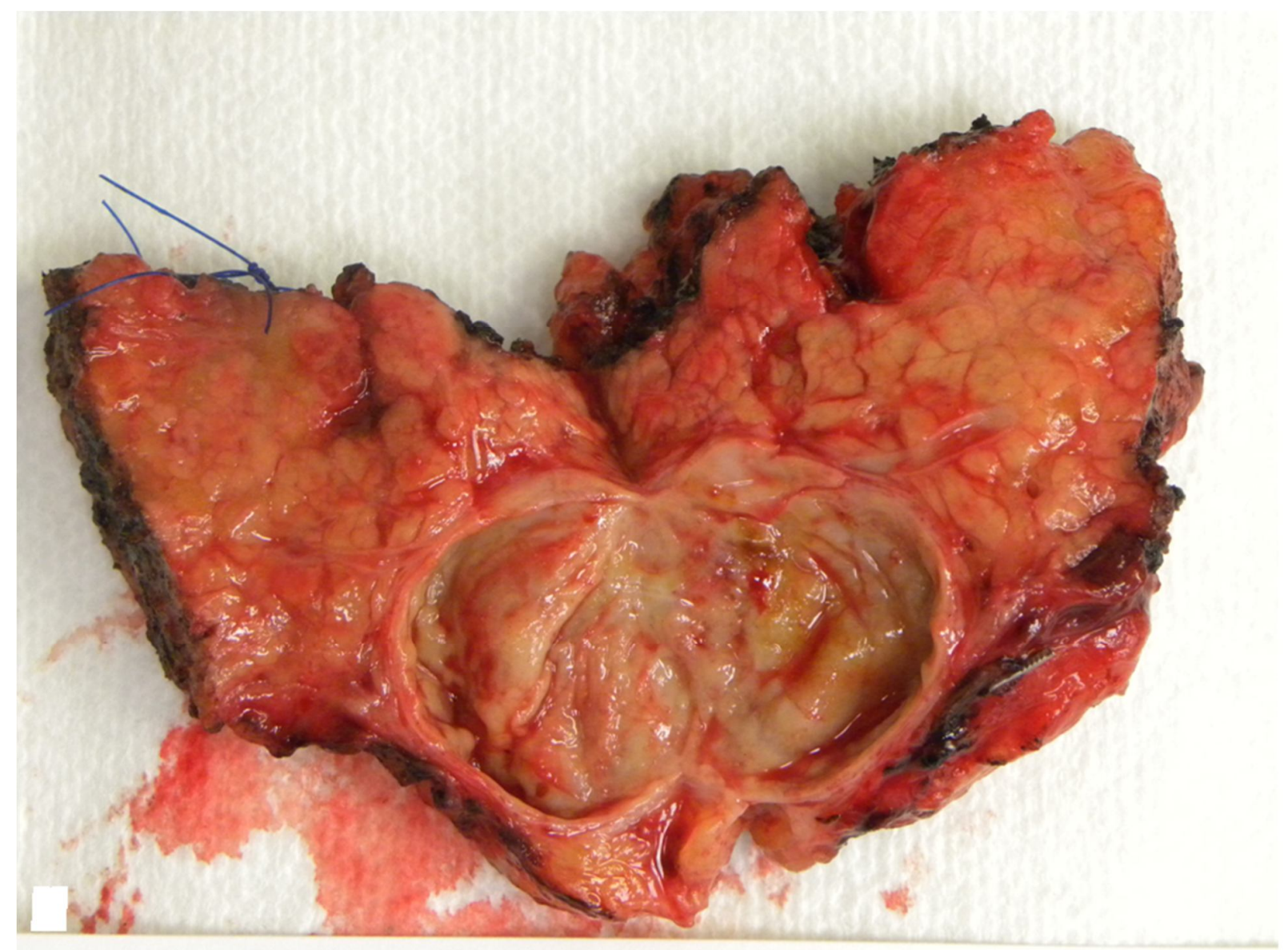

Fig. 2B. Photomicrograph showing well differentiated cytso endpcrine neoplasm (original magnification $\mathrm{x} 100$ ). 


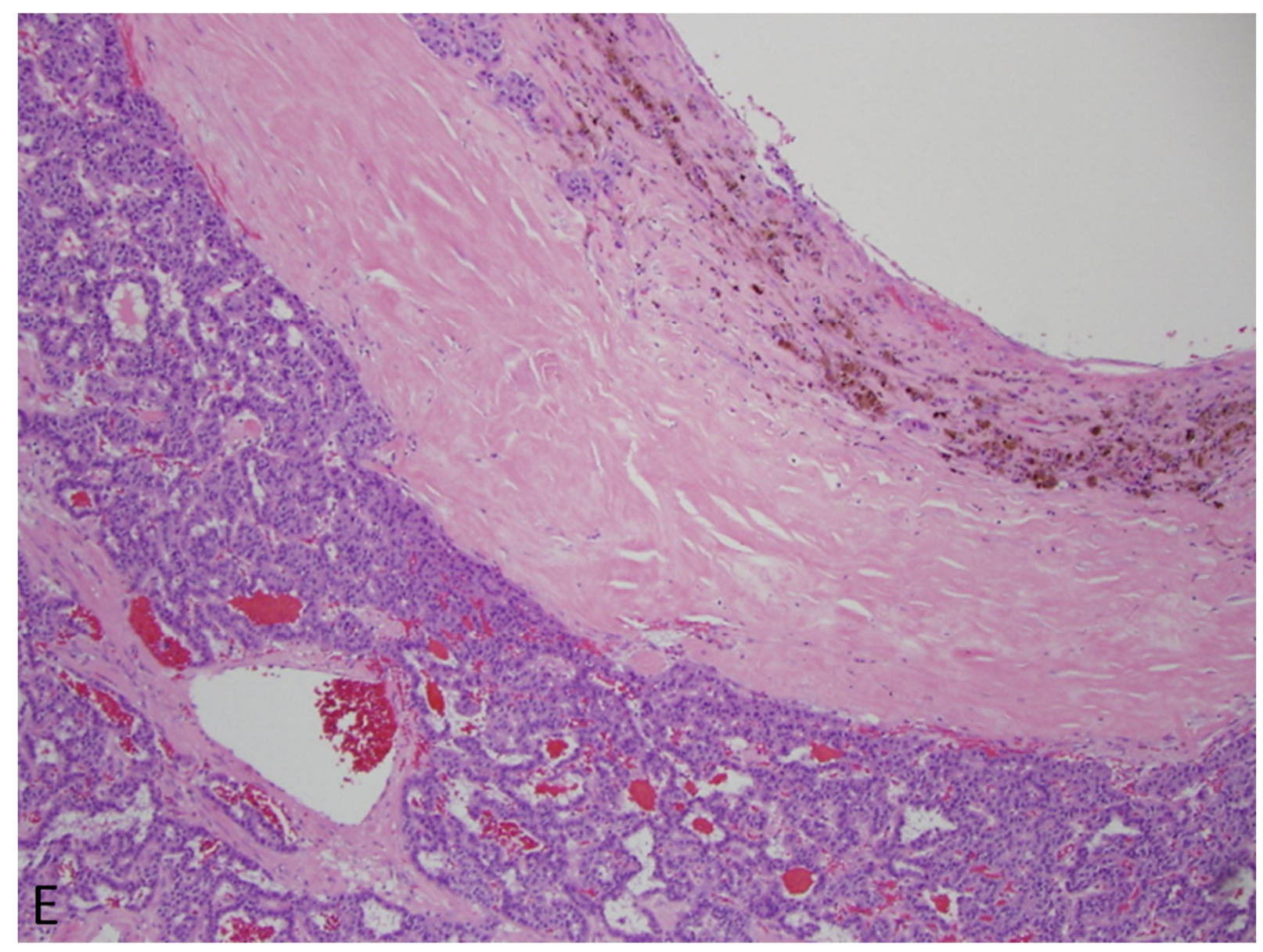

